\title{
Advantage of a routine Reiter protein complement-fixation test in the serodiagnosis of syphilis in pregnancy
}

\author{
C. A. MORRIS \\ From the Public Health Laboratory Service, Bristol
}

SYNOPSIS One hundred and twenty-seven $(0 \cdot 3 \%)$ reactive serological tests for syphilis were obtained by routine examination of sera from 35,912 antenatal patients.

Forty-eight $(38 \%)$ of these reactive sera were associated with reactive fluorescent treponemal antibody and Treponema pallidum immobilization results and these patients were therefore considered to show serological evidence of treponemal infection. Sera from 13 of these 48 patients (27\%) gave reactive Reiter protein complement-fixation tests in the absence of detected 'reagin' antibody. Seventy-nine patients showed non-specific biological false positive reactions to the routine tests.

Following clinical assessment of these serologically reactive patients, approximately one in 100 immigrant and one in 2,500 non-immigrant pregnant women examined in this series were treated with penicillin; this represented just over half the number of patients with serological evidence of a treponemal infection, a ratio which was similar for immigrant and native born women. Yaws was the likely treponemal infection in the majority of infected immigrants. The significance of the serological results and the advantages of the Reiter protein complement-fixation test are discussed.

Each year serum samples from thousands of antenatal patients are examined to identify the very small proportion of these women who have syphilis. It is the aim of a routine diagnostic laboratory to detect all sera containing treponemal antibody, the clinical significance of which may then be assessed by the physician. Serum from most patients with untreated active syphilis contains non-specific 'reagin' antibodies, which, by using highly sensitive tests, are more easily and cheaply detected by simple serological means than are specific treponemal antibodies. It is the practice of many laboratories to select the sera which contain 'reagin' antibodies by preliminary screening tests with lipoidal antigens, eg, Maltaner cardiolipin and VDRL antigens. These selected sera are then further examined for the presence of treponemal antibodies, commonly by means of a Reiter protein complement-fixation test. Some patients with early, late, latent, or treated syphilis have serum devoid of 'reagin' antibodies but containing treponemal antibodies; these patients cannot be detected serologically by a preliminary screening with lipoidal antigen tests alone.

Received for publication 26 March, 1968.
The present study was undertaken to determine what proportion of sera from antenatal patients contained treponemal antibodies in the absence of reagin antibodies; with this figure and additional serological and clinical information it is possible to decide whether the Reiter protein complementfixation test, if applied to all antenatal sera in addition to lipoidal antigen tests, contributes substantially to the identification of sera from patients with treponemal infection.

\section{MATERIALS AND METHODS}

SERA Serological tests were performed on all sera from pregnant women submitted from five centres to the Bristol Public Health Laboratory during the period January 1966 to June 1967. Most blood samples had had a preliminary blood group analysis but none had been selected by preliminary lipoidal antigen tests. Sera were stored at $4^{\circ} \mathrm{C}$ and inactivated for 30 minutes at $56^{\circ} \mathrm{C}$ before testing.

ROUTINE SEROLOGICAL TESTS The Reiter protein complement-fixation test (RPCF) and a Wassermann reaction (CLCF), using Maltaner cardiolipin antigen, were used routinely. The method was an adaptation of the 
modified Whitechapel technique (Association of Clinical Pathologists, Broadsheet 41) using commercial antigens (Burroughs Wellcome \& Co.) and WHO perspex haemagglutination plates in a one-hour fixation test at $37^{\circ} \mathrm{C}$. Sera were examined at a dilution of 1 in 5 in veronal-buffered saline. The test dose of complement for the diagnostic row in the CLCF was 1.25 MHD and that for the RPCF and control row was 1.00 MHD.

The VDRL slide test (US Public Health Service Manual of Serologic Test for Syphilis, 1964) was done using stabilized antigen (Burroughs Wellcome \& Co.).

Positive control serum Aliquots of a reconstituted freeze-dried stock of positive control serum from a single donation of blood was tested quantitatively on each occasion to check the day-to-day sensitivity of the tests.

REFERENCE LABORATORY TESTS Sera giving reactive results in one or more routine tests on two samples of serum from the same patient were sent to the Venereal Disease Reference Laboratory, the London Hospital, for Treponema pallidum immobilization (TPI), fluorescent treponemal antibody (FTA), and repeat routine tests.

\section{RESULTS}

SEROLOGICAL RESULTS Sera from 35,912 pregnant women were examined. One hundred and twentyseven of these gave reactive results in one or more of the routine tests and 48 were found to give reactive TPI or FTA tests (Table I).

Thirty-five of the 48 TPI or FTA reactive sera also gave reactive lipoidal antigen tests; 27 of these sera were associated with reactive Wassermann tests and eight with reactive VDRL slide tests but non-reactive Wassermann tests. Thirteen of these 48 sera were detected by a reactive RPCF test and would not have been identified by tests for 'reagin' antibody.

The same serum samples when examined at the routine and reference laboratories showed close agreement in the reactions to the routine tests. The maintenance of a high degree of sensitivity of the routine laboratory tests resulted, however, in some loss of specificity of the RPCF reaction; seven of the 48 TPI or FTA reactive sera gave reactive tests the routine laboratory which were non-reactive the corresponding tests in the reference laboratory; three of these sera gave reactive reagin tests ane four reactive RPCF tests in the routine laboratory only. Forty-five of the 82 patients with reactize RPCF tests also had reactive TPI or FTA results whereas 17 were associated with non-reactive TPI or FTA tests and 20 patients either had an invali TPI/FTA result or could not be examined furtherp. The majority of sera (32 of 39 sera) with both reactive RPCF and reagin tests were also TPI or FTA positive. However, only approximately one in three sera (13 of 43$)$ which gave a reactive RPCF test $\vec{f}$ association with non-reactive reagin tests was found to be TPI or FTA positive.

Routine serological tests related to clinica significance The 48 patients who, in addition one or more reactive routine tests, were also show to have reactive TPI or FTA serology were classified as having serological evidence of a treponemat infection (Table II). The remaining 79 patients with reactive routine tests were considered to be showing biological false positive serological reaction related to pregnancy or other non-treponemâึ conditions.

After clinical assessment, 39 of the 48 patients with serological evidence of treponemal infection were classed as having probable syphilis, 34 in the latent or cured stages, one with neurosyphilis, and four with congenital syphilis; however, yaws could not be excluded with certainty in some of these patients. Nine patients were diagnosed as having yaws or an allied treponemal infection; one of these women was of European origin but had spent severat years in a prisoner-of-war camp in the Philippines

Sixteen of the patients with probable syphilis and

TABLE I

SEROLOGICAL TESTS FOR SYPHILIS ON 35,912 ANTENATAL PATIENTS

Routine Serological Test

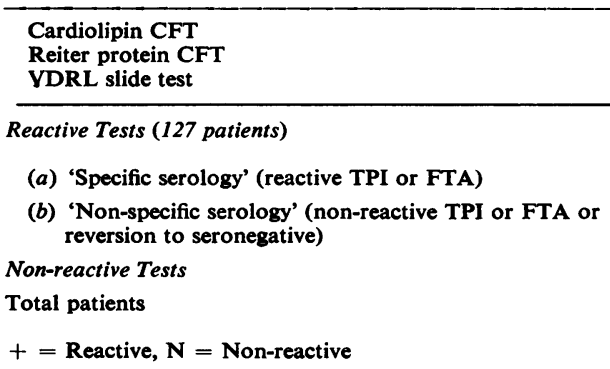

Result (Serological Group)

$\begin{array}{lllllllll}++ & + & + & + & \mathbf{N} & \mathbf{N} & \mathbf{N} & \mathbf{N} & \mathbf{N} \\ + & + & \mathbf{N} & \mathbf{N} & + & + & \mathbf{N} & \mathbf{N} & \omega \\ + & \mathbf{N} & + & \mathbf{N} & + & \mathbf{N} & + & \mathbf{N} & 0\end{array}$

Patients

\begin{tabular}{|c|c|c|c|c|c|c|c|c|}
\hline 48 & 24 & 1 & 2 & - & 7 & 13 & 1 & - \\
\hline 79 & - & 4 & 5 & 26 & 3 & 30 & 11 & - \\
\hline 5,785 & - & - & - & - & - & - & - & \\
\hline 5,912 & 24 & 5 & 7 & 26 & 10 & 43 & 12 & 35 \\
\hline
\end{tabular}


TABLE II

ROUTINE SEROLOGICAL REACTIONS IN RELATION TO CLINICAL INDICATIONS FOR TREATMENT AND THE IMMIGRATION STATUS OF 48 ANTENATAL PATIENTS WITH SEROLOGICAL EVIDENCE OF A TREPONEMAL INFECTION

Routine Serological Test Result (Serological Group)

\begin{tabular}{|c|c|c|c|c|c|c|c|}
\hline $\begin{array}{l}\text { Cardiolipin CFT } \\
\text { Reiter protein CFT } \\
\text { VDRL slide test }\end{array}$ & & $\begin{array}{l}+ \\
+ \\
+\end{array}$ & $\begin{array}{l}+ \\
+ \\
\mathbf{N}\end{array}$ & $\begin{array}{l}+ \\
\mathbf{N} \\
+\end{array}$ & $\begin{array}{l}\mathbf{N} \\
+ \\
+\end{array}$ & $\begin{array}{l}\mathbf{N} \\
+ \\
\mathbf{N}\end{array}$ & $\begin{array}{l}\mathbf{N} \\
\mathbf{N} \\
+\end{array}$ \\
\hline Immigrant Status & $\begin{array}{l}\text { Clinical Indications } \\
\text { for Current Treatment }\end{array}$ & \multicolumn{6}{|c|}{ No. of Patients in Each Serological Group } \\
\hline Immigrant (20 patients) & $\begin{array}{l}\text { Present } \\
\text { Absent }\end{array}$ & $\begin{array}{l}5 \\
3\end{array}$ & - & 1 & $\begin{array}{l}2 \\
4\end{array}$ & $\begin{array}{l}3 \\
2\end{array}$ & - \\
\hline Non-immigrant ( 28 patients) & Present & $11^{1}$ & - & 1 & 1 & $1^{2}$ & 1 \\
\hline Total patients (48) & Absent & $\begin{array}{r}5 \\
24\end{array}$ & $\begin{array}{l}1 \\
1\end{array}$ & $\overline{2}$ & $\frac{-}{7}$ & $\begin{array}{r}7 \\
13\end{array}$ & $\overline{1}$ \\
\hline
\end{tabular}

${ }^{1}$ Includes two patients re-treated for previously diagnosed treponemal infection and one patient who refused treatment.

${ }^{2}$ Patient re-treated for previously diagnosed and treated syphilis.

six with yaws were treated for these conditions for the first time, one patient refused treatment and further medical advice, and one other woman who showed no evidence of active disease was not given chemotherapy. Three patients with a past history of treated syphilis were prescribed a further course of penicillin; 18 patients with treated syphilis and three with treated yaws were kept under observation. There were no infants with congenital syphilis amongst the offspring of those patients who remained under medical care.

Clinical significance of treponemal antibody in serum devoid of 'reagin' antibodies Seven of the 13 patients with reactive RPCF and TPI/FTA tests unassociated with 'reagin' antibodies had a history of syphilis treated during the preceding three to six years; one patient had a history of treated yaws. Three patients were treated for the first time after these serological tests and a fourth received a second course of penicillin. One patient who showed no evidence of active infection was not given antibiotics.

Five of these 13 patients were West Indians.

Serological evidence of treponemal infection in relation to nationality of patient The nationality of all patients from whom serum was received by this laboratory has not been recorded, but a representative sample from the antenatal clinics shows that about $2 \%$ of their patients are immigrants, if this regional population is considered as a whole. Certain clinics care for a higher proportion of immigrant women; in the City and County of Bristol (from which nearly 19,000 of the present series of sera were submitted) Wofinden (1965) has estimated that $4 \%$ of live births are to immigrant mothers. This Bristol population includes a considerable proportion of West Indians a number of whom may be expected to have serological evidence of yaws.
For the current study $4 \%$ of the Bristol clinic sera and $2 \%$ of the remaining sera are estimated as having come from immigrants who therefore constituted approximately 1,100 patients.

Twenty of 48 patients with serological evidence of treponemal infection are immigrants, 17 being West Indian, two Chinese, and one Sicilian (Table II).

Serological evidence of treponemal infection was found in approximately $2 \%$ of the immigrant sample $(20$ of 1,100$)$ and in $0.08 \%$ of the women born in the United Kingdom (28 of 34,094).

Eleven immigrant and 15 native born women were prescribed antibiotic treatment; this represents $55 \%$ and $53.6 \%$ respectively of these two groups of patients with serological evidence of treponemal infection.

\section{DISCUSSION}

The annual reports on the State of the Public Health show that until 1966 the world-wide increase in venereal disease was reflected in the notifications of infectious syphilis in the United Kingdom; 2,118 cases in 1965 represents an increase of $22 \%$ over the figures for the previous year which were themselves $25 \%$ higher than the notifications for 1963. The report of 1,819 cases for 1966 , however, shows an appreciable decline in infectious syphilis in England and Wales (amounting to $14 \%$ ) despite an increase in the proportion of females to males. This trend is reflected by a decrease in the proportion of positive serological tests for syphilis in pregnancy, and in the reported cases of congenital syphilis. Nevertheless, 262 cases of congenital syphilis were reported in 1966 as compared with 275 in 1965 and 258 in 1964.

In agreement with Wilkinson and Rayner (1966) the TPI and FTA tests have been accepted as the 
most reliable verification tests at present available for the specific detection of treponemal antibodies; a non-reactive TPI test has been considered in this study to exclude a treponemal infection. Foster, Nicol, and Stone (1959), however, have described the persistence of a positive RPCF test in treated syphilis when the TPI test was negative. Similarly, negative TPI tests in patients with ocular or neurosyphilis may occur (Smith, 1967). Where there is an apparent discrepancy between the clinical and serological findings the fluorescent treponemal antibody absorption test may be useful, since this test is claimed to be more specific and sensitive than the TPI (Stevens, Boylan and Memoli, 1967).

These sera from women in their first or subsequent pregnancy gave $0.3 \%$ reactive serological results which lies within the range of $0.05 \%$ and $0.42 \%$ given by Pritchard, Mechie, McHugh, and Boot (1967) for women examined during their first pregnancy. The proportion of non-specific reactive routine tests was $62 \%$ in the present series but this proportion may be expected to rise during the course of epidemic infections or following a widespread immunization programme such as vaccination. The $0 \cdot 10 \%$ RPCF false positive reactions ( 37 of 35,785 patients) in this series compares favourably with that of not greater than $0.55 \%$ found by Sequeira (1959) who examined sera from males as well as females.

In the south-west of England the immigrant population is small when compared with some areas of the United Kingdom. In this regional population only half of those patients with serological evidence of treponemal infection in pregnancy were found to require antibiotic treatment. In the present study approximately one in 100 immigrant and one in 2,500 non-immigrant pregnant women were treated for a treponemal infection.

It is evident from these results that routine tests on antenatal sera, if restricted to the detection of 'reagin' antibodies, fail to identify a third of the patients who have serological evidence of treponemal infection. The majority of patients with active syphilis have 'reagin' as well as treponemal antibodies. Since most patients are examined serologically for syphilis only once in each pregnancy, it is important to ensure that as few as possible of? those with treponemal infection remain undetected $=$ by this serological diagnostic screen. As one cannot $t^{\rho}$ differentiate serologically between the different? trepanematoses, such as yaws and $T$. pallidum infections, the significance of reactive serological findings must be gauged by clinical assessment.

The continuing need to maintain adequate sero-s logical supervision of pregnant women has beenemphasized (Lancet, 1967). This supervision is necessary in each and every pregnancy both for thecw welfare of the infected mother and her unborn child and for the elimination of a reservoir of $T$. pallidum?

This paper is presented to support a belief that the diagnosis of syphilis in pregnancy is a currentos medical problem which justifies periodic reappraisalc of routine laboratory methods. The addition of a Reiter protein complement-fixation test to the tests for 'reagin' antibody adds not only specificity $\vec{z}$ but also sensitivity (Sequeira, 1962). The reliabilityo and limitations of the RPCF test have been summar- ized by Bekker (1962). The present study confirms that in antenatal serological diagnosis the application of a routine RPCF test results in a significanteo increase in the number of reactive sera identifiedoo at the cost of only a small amount of time and money.

I am grateful to Dr A. E. Wilkinson for performing theô TPI and FTA tests, and to Mr R. P. Hobbs, FIMLT, for technical assistance. I am also indebted to $\mathrm{Dr} H$. R Cayton for helpful advice on the presentation of the paper.

\section{REFERENCES}

Bekker, J. H. (1962). Brit. J. vener. Dis., 38, 131.

Foster, W. D., Nicol, C. S., and Stone. A. H. (1959). Ibid., 35, 181 Lancet (1967). 2, 503.

Pritchard, J. G., Mechie, A. M., McHugh, J. G., and Boot, P. A. (1967). Brit. J. vener. Dis., 43, 18

Sequeira, P. J. L. (1959). Ibid., 35, 139.

- (1962). Ibid., 38, 9.

Smith, J. L. (1967). J. Amer. med. Ass., 199, 128.

Stevens, R. W., Boylan, J., and Memoli, A. J. (1967). Amer. J. clin Path., 47, no. 3, 408. Wilkinson, A. E., and Rayner, C. F. A. (1966). Brit. J. vener. Dis. N

Wofinden, R. C. (1965). The Health of Bristol in 1965. Report of the Medical Officer of Health. 